\title{
EL CABILDO DE INDÍGENAS: DE LA OPRESIÓN COLONIAL A LA RESISTENCIA CONTEMPORÁNEA. EL CASO DEL PUEBLO QUILLASINGA DE MOCONDINO (SAN JUAN DE PASTO, COLOMBIA)
}

\author{
THE COUNCIL OF INDIGENOUS: SINCE THE COLONIAL OPPRESSION \\ TO A CONTEMPORARY RESISTANCE. THE CASE OF MOCONDINO'S \\ INDIGENOUS PEOPLE (PASTO, COLOMBIA)
}

\author{
Franco Ceballos Rosero*
}

\begin{abstract}
La institución del Cabildo de Indígenas -de origen Colonial- en Colombia ha sufrido varias transformaciones históricas que la han convertido, en la actualidad, en la principal organización comunitaria para la defensa de la autonomía de los pueblos originarios, siendo, en el caso del pueblo quillasinga de Mocondino (San Juan de Pasto), el elemento que conecta el pasado ancestral con el presente de resistencia y reconstrucción histórica ante los atropellos de la contemporaneidad y la desaparición jurídico-política hacia 1948, a partir de la idea de que el pasado se encuentra adelante, marcando el sendero por donde habrá de andarse y desandarse los caminos del futuro. De ser una institución Colonial de control social y sometimiento de los pueblos originarios, el Cabildo se ha convertido en el baluarte para la resistencia comunitaria ante los atropellos que en la república no han cesado, además del elemento que dimensiona la historia de los mocondinos como un todo indisoluble y en movimiento, bajo las actuales coyunturas político-jurídicas iniciadas en 1991 con la expedición de la Ley 21 (Convenio 169 de 1989 de la OIT) y la Constitución Política actual.
\end{abstract}

Palabras claves: Cabildo de Indígenas, Mocondino (Colombia), etnohistoria, etnoliteratura, resistencia indígena.

The institution of the Council of Indigenous, Colonial origin, Colombia has suffered a series of historical transformations that have become, at present, the main community organization for the defense of the autonomy of indigenous peoples, being, in the case quillasinga's people of Mocondino (San Juan de Pasto), is the element that connects the ancient past to the present and historical reconstruction resistance against the abuses of contemporary legal and political demise by 1948, based on the idea that the past is ahead, marking the path where walk and to retrace must roads of the future. From a Colonial institution of social control and subjugation of native peoples, the council has become the stronghold for community resistance to the abuses in the republic have continued addition of the element dimensions Mocondino's history as a indissoluble and moving, under the current political and legal situations initiated in 1991 with the enactment of Law 21 (Convention 169/1989 of the ILO) and the current Constitution.

Key words: Indigenous council, Mocondino (Colombia), ethnohistory, ethnoliterature, Indigenous Resistence.

\section{Introducción}

La historia que te voy a contar no me la contó nadie. Bueno, me la contó mi abuelo, pero él me advirtió que solo la entendería cuando la soñara. Así que te cuento la historia que soñé y no la que me contó mi abuelo.

Subcomandante Marcos (1995).

En la actualidad, y por circunstancias históricas, políticas y económicas diversas y heterogéneas, el pueblo y territorio indígena de Mocondino, localizado al oriente de la ciudad de Pasto (Colombia), ha iniciado varios difíciles procesos de recuperación y revitalización de sus memorias, identidad y territorio ancestrales acallados hacia 1948 por una resolución del entonces Ministerio de la Economía Nacional que declaró extinto el resguardo indígena, con un sinnúmero de dificultades y oposiciones de todo tipo, desde las políticas a las jurídicas, que ven en estos procesos serias amenazas a los modelos político-administrativos existentes. La amenaza más seria que estos procesos de recuperación de la identidad y territorios étnicos representan se encuentran en la posibilidad

\footnotetext{
* Universidad Cooperativa de Colombia. Instituto Andino de Artes Populares (IADAP) de la Universidad de Nariño. Colombia. Correo electrónico: franco.ceballosr@campusucc.edu.co.
} 
de la desmembración del territorio del municipio de Pasto, cuya ciudad está rodeada de pueblos de indios que fueron desaparecidos hacia la primera mitad del siglo XX, y que, de volver a la vida jurídico-política colombiana, marcarían la desaparición de los territorios rurales aledaños a la ciudad, de los que se abastece de agua, oxígeno, personas, animales, minerales y plantas que son indispensables para su existencia y que hoy por hoy controla. Si los pueblos de indios que existieron desde la Colonia (y mucho antes en algunos casos) renacen a la vida jurídica y política, toda acción del poder local, regional y nacional estaría sujeta al desarrollo del derecho fundamental a la consulta previa de la que habla el Convenio 169 de la OIT (Ley 21 de 1991) que en Colombia goza de rango constitucional, al tenor de lo dispuesto en el artículo 93 de la Constitución Política.

Estos procesos de etnogénesis (Bengoa 2000), etnización (Büschges y Pfaff-Czarnecka 2003) o reindigenización (Perugache 2012; Chaves 2001; Zambrano 2001), visibilizan que diversos actores sociales, que se creyeron extintos del mapa político y jurídico de la nación colombiana hacia la primera mitad del siglo XX gracias a la implementación de la Ley 89 de 1890 que buscaba la disolución de los resguardos de origen colonial, reaparezcan para resistir problemas derivados del modelo de civilización imperante y sus políticas desarrollistas y "humanitarias"; resistencias que se configuran en el presente pero a partir del pasado, su reinterpretación o reinvención desde una memoria retrospectiva y fluida (Wachtel 2009), memoria que no se recupera solo para la contemplación pasiva de lo que fue, sino como dice Rappaport, para incentivar a los pueblos para una militancia en el presente (2005[1994]), ante todo porque el futuro, bajo la lógica del desarrollo, ha perdido su poder "esperanzador" y se hace urgente dirigir la mirada hacia el presente bajo el horizonte del pasado, en particular para los pueblos originarios si se piensan como alternativa de vida.

Durante la primera mitad del siglo XX, la existencia y devenir de los habitantes de los resguardos indígenas quillasingas, y a partir de 1950 de los pobladores de los corregimientos rurales y periurbanos de Pasto, ha sido abordada desde distintas perspectivas: históricas (Afanador 1977; Muñoz 2003; Martínez \& Portilla 1992; Perugache 2014), sociológicas (Fals-Borda 1959) y antropológicas (Chaves M. 1986; Melo 1992; Mamián
2000), y de todas se concluye que, de una u otra forma, la disolución de los resguardos y cabildos quillasingas tuvo como eje la desestructuración comunal a partir de los imaginarios ilustrados introducidos durante la independencia y triunfantes en la república a la manera conservadora y clerical de Núñez y Caro en 1886, cuando se consolidó el proyecto de Estado colombiano actual (Calderón 1895; Malagón 2006); todo eso sumado a una serie de amenazas y coerciones jurídicas, políticas y económicas por parte del Estado, tendientes a implantar el régimen liberal necesario para la inserción de la república en las lógicas de la modernidad ilustrada, progresista, desarrollista y extractivista que impera en América Latina desde entonces, y que ha sido la fuente de la injusticia planetaria (Acosta \& Martínez 2011c).

\section{El despertar del pasado}

Dicen que la noche esconde, que es más segura; por eso hemos sobrevivido en la profunda noche que es el olvido, lejos de la endiablada búsqueda de la Razón. En el derecho está el día; en el reverso nosotros, agazapados a la espera de nuestro turno para gobernar (Ceballos 2014:170).

Si bien en 1948 el Ministerio de Economía Nacional declaró extinto el resguardo indígena de Mocondino, y de paso su Cabildo de Indígenas según lo estipulaba la Ley 89 de 1890, la identidad étnica se mantuvo latente en las formas comunitarias de vida, a la espera del desencanto al que fueron sometidos los imaginarios e identidad étnica por la institucionalidad, que miraba en estos obstáculos al "progreso" y "desarrollo" del país, que necesitaba territorio y riquezas para nutrir al naciente Estado que aún hoy no termina de consolidarse.

Reza el artículo 39 de la Ley 89 de 1890: Hecha la división de los terrenos de Resguardo, cesarían las funciones de los Cabildos de las parcialidades. Dice la resolución 12 del 20 de enero de 1948 del Ministerio de la Economía Nacional que reposa en el Archivo General de la Nación: Los indígenas del resguardo de Mocondino, en la ciudad de Pasto, departamento de Nariño, han solicitado en repetidas ocasiones que, de conformidad 
con las normas establecidas en la Ley 19 de 1927 y el Decreto Legislativo 1421 de 1940 , proceda a declarar la extinción del dicho resguardo para poder solicitar cada parcialista la adjudicación definitiva de las parcelas que desde tiempo atrás han venido ocupando y poseyendo sin interrupción alguna. / Teniendo en cuenta tales solicitudes ha adelantado tendientes a obtener los medios de juicio suficientes para conocer la calidad jurídica del requerido resguardo, su situación de hecho, el número de componentes y posibles adjudicatarios, área de los terrenos explotados a incultos, datos estos que se han logrado y que aparecen en el informativo correspondiente [...] Resuelve: Primero. -Declárese que el llamado 'Resguardo de Mocondino', situado en el municipio de PASTO, Departamento de Nariño, carece de la titulación necesaria para tener la calidad de Resguardo de Indígenas y que, en consecuencia, sus terrenos no han salido del patrimonio del Estado [énfasis mío].

$\mathrm{Y}$ aunque muchos pobladores de Mocondino perdieron la noción de ser indígenas, sus prácticas sociales siguieron permeadas por lo comunitario, desde las mingas a los gobiernos locales y fiestas, ya no como cabildos e indígenas, sino como juntas de acción comunal y campesinos que mantuvieron prácticas de su pasado ancestral, aunque ya no se visibilizaran como tal. Entre los ciudadanos de Mocondino sobrevivieron los indígenas a la espera de su turno para gobernar.

\section{Antecedentes}

Fueron dos los detonantes para que la memoria e identidad étnica volviera a resurgir entre las cenizas en Mocondino: la construcción de la vía Panamericana perimetral y los planes de expansión urbana de la ciudad con la consecuencial incidencia en el manejo del acueducto comunitario.

Verá, mi profe, que hace solo unos años la vida era distinta por aquí, sin carretera, sin barrios de invasión ni planes para apoderarse de nuestra agua. Mi papá, que en paz descanse, dizque sabía mandar a castigar a todos los comuneros que maltrataran los animales cuando había sido gobernador, no como ahora que todo es negocio y productividad, y los pobres animalitos se los martiriza de todas las formas. Eso porque como que había sido amigo -él nunca me lo contó, pero por ahí lo averigüé- de Don Juanito, el médico de Jenoy, que cuentan sabía irse a los bosques del volcán Galeras a conversar con los animales, en especial con un animal hermano de sangre nuestro. Pero, mi profe, esos eran otros tiempos: hoy aunque queramos la juventud no entiende, porque ni en el colegio o la escuela le enseñan las cosas que sabían enseñar los mayores de antes, que si era de poner a las bestias a trabajar, lo hacían, pero trabajando parejo, parejo. Hoy los muchachos ya no escuchan, ya no obedecen, y lo que es peor, ya no se les puede decir nada, porque todo es considerado maltrato. Y todo por culpa de esas ideas dizque revolucionarias de otra educación. ¡Como si antes no hubiéramos estado mejor que ahora! (Ceballos 2014:170).

La construcción de la vía Panamericana perimetral para la ciudad de San Juan de Pasto, que busca el desahogo vehicular del tráfico pesado que agobia la urbe, causó el descontento de una parte de la población del territorio de Mocondino (2010), que no viendo en esto las ya desgastadas perspectivas de desarrollo y progreso con las que se desasrticuló a los pueblos originarios en el municipio de Pasto y otras regiones de Colombia (Mamián 2000), se opusieron, desde el principio, al paso de la carretera sin unas políticas claras de mitigación de los efectos catastróficos, como la división del territorio (física, comunitaria, espiritual) y el paso cercano a los páramos que abastecen de agua y oxígeno al territorio, y que son parte de la cuenca oriental del lago Guamuézque que va hacia la Amazonia.

Paralelo a esta problemática, la Alcaldía de Pasto intentó incidir en la administración del acueducto de la comunidad de Mocondino, en un primer momento, mediante inversiones para el mejoramiento del acueducto comunitario patrocinadas por el BID en 2010, que fueron rechazadas por la comunidad porque estaban condicionadas a la realización de cambios en las estructuras administrativas propias; y después mediante el avance de los asentamientos 
urbanos sobre el territorio de Mocondino y una política de incidencia en el manejo comunitario del agua, lo que derivó en un conflicto jurídico sin solución hasta la fecha y que implica la construcción de un acueducto paralelo al existente para una nueva comunidad, que apeló a la acción constitucional de tutela (amparo) para obligar al gobierno local a empezar la obras para el nuevo acueducto ante la oposición comunitaria, mismas que hasta la fecha no han podido iniciarse pese al fallo favorable para los tutelantes (Ceballos 2013). Así se puede resumir este conflicto:

El 9 de febrero de 2012 la Jueza Cuarta Civil Municipal de Pasto tuteló el derecho fundamental al agua potable de varios pobladores del sector de Canchala Alto (creado en la vereda Canchala de Mocondino por una resolución de la Gobernación de Nariño en el año 2010) que aspiraban ser beneficiarios de la construcción de un acueducto paralelo al existente en Mocondino (Patricia Dávila, Heriberto de la Cruz y Polibio Jácome), dentro de un proyecto de vivienda de expansión urbana. Esta sentencia de tutela (que tuvo una defensa execrable por parte de la abogada apoderada de las Juntas Administradoras del Agua de Mocondino, sobre todo teniendo en cuenta que el sector no es de expansión urbana) desconoció varios hechos fundamentales: que en el sector donde se pensaba construir el acueducto no existían asentamientos urbanos para los que se tuteló ese derecho, y que los tutelantes tenían el servicio de agua potable, por lo que no existía vulneración del derecho que se pretendió amparar. Para infortunio de las Juntas Administradoras del Agua de Mocondino, la abogada que los representaba no realizó una defensa adecuada ni impugnó la sentencia de tutela, lo que acarreó que la misma quedara en firme. Ante la imposibilidad jurídica de ejercer oposición a una acción de tutela en firme, varios pobladores de Mocondino retomaron su pasado ancestral y se opusieron a la misma mediante el denominado Derecho Mayor, al tenor de lo presupuestado en la Constitución Política (en especial el ar- tículo 93) y la Ley 21 de 1991. El Cabildo renaciente ejerció el suficiente poder para propiciar un "acuerdo" de cumplimiento de la acción de tutela con los accionantes y la Alcaldía de Pasto el 12 de julio de 2012, para que esta se ejecute en los siguientes veinticinco años (!), hecho curioso si se tiene en cuenta que la acción de tutela es una acción residual y que implica un cumplimiento inmediato (Allroggen yArturo 2013).

\section{El Cabildo renaciente}

Ante las problemáticas descritas, desde el 29 de abril de 2012 los pobladores que se reconocen como actores de origen quillasinga han librado una dura resistencia a estas problemáticas, teniendo como horizonte el pasado ancestral latente dentro de sus imaginarios y prácticas cotidianas, siendo atacados por la institucionalidad y los particulares como actores opuestos al "progreso" y oportunistas de turno, encontrando serias resistencias en lo político, jurídico y social al proceso de revitalización de la identidad étnica, encontrándose los mocondinos en serio peligro de extinción si no se invierten las mentalidades utilitarias con las que se mide todo en la actualidad, situación que merece la atención especial del Estado y la academia, con el fin de evitar la consumación del genocidio propiciado por las políticas y práctica jurídicas de blanqueamiento (Lopera-Mesa 2010; Gross 2012) que imperan, aun hoy de forma mimética e hipócrita, en el proceso inconcluso de construcción de la nación colombiana y la integración jurídica de los pueblos originarios a la misma (Vasco L. 2010; Vasco L. G. 2011).

La comunidad de Mocondino que se reconoce como de origen indígena retomó el rumbo de sus destinos al tenor de lo estipulado en las leyes 89 de 1890 (Art. 3) y 21 de 1991 (Art. 1), además de la normatividad constitucional que les favorece (artículos 1, 7, 8,10, 11, 63, 70, 72, 79, 93, 246, 285,330 y 365 ). Destacamos los siguientes textos normativos:

Ley 89 de 1890 Artículo $3^{\circ}$. En todos los lugares en que se encuentre establecida una parcialidad de indígenas habrá un pequeño Cabildo nombrado por estos conforme a sus costumbres. El período de duración de dicho Cabildo será de un año, de $1^{\circ}$ de enero 
a 31 de diciembre. Para tomar posesión de sus puestos no necesitan los miembros del Cabildo de otra formalidad que la de ser reconocidos por la parcialidad ante el Cabildo cesante y a presencia del Alcalde del Distrito. / Exceptúense de esta disposición las parcialidades que estén regidas por un solo Cabildo, las que podrán continuar como se hallen establecidas.

Ley 21 de 1991 Artículo $1^{\circ}$. 1. El presente Convenio se aplica: a) A los pueblos tribales en países independientes, cuyas condiciones sociales, culturales y económicas les distingan de otros sectores de la colectividad nacional, y que estén regidos total o parcialmente por sus propias costumbres o tradiciones o por una legislación especial; b) A los pueblos en países independientes, considerados indígenas por el hecho de descender de poblaciones que habitaban en el país o en una región geográfica a la que pertenece el país en la época de la conquista o la colonización o del establecimiento de las actuales fronteras estatales y que, cualquiera que sea su situación jurídica, conservan todas sus propias instituciones sociales, económicas, culturales y políticas, o parte de ellas. 2. La conciencia de su identidad indígena o tribal deberá considerarse un criterio fundamental para determinar los grupos a los que se aplican las disposiciones del presente Convenio. 3. La utilización del término "pueblos" en este Convenio no deberá interpretarse en el sentido de que tenga implicación alguna en lo que atañe a los derechos que pueda conferirse a dicho término en el derecho internacional [énfasis mío].

Como superior de la Autoridad propia quedó elegido por la comunidad el señor Silvio Naspirán Jojoa (gobernador), quien desde entonces dirige la resistencia indígena junto a Isidro Jojoa, Gabriela Lasso, Rosario Jojoa, Lorena Achicanoy, José y Fabio Naspirán, entre otros, siendo actores sociales críticos que buscan reconstruir su historia y mantener su identidad ante el avance de la ciudad y sus dinámicas de destrucción.

Esta vara de justicia que llevo conmigo, mi profe, no solo indica que soy autoridad de mi gente, sino que soy un guerrero. Pero no para la guerra, sino para la supervivencia de los míos y del territorio que lo están acabando con carreteras como la perimetral y los planes de llevarse nuestra agua sin pedir permiso. Uno cuando va a la casa de otra persona pide permiso, pero acá ni eso por parte del gobierno. Hoy que nos toca resistir le digo que esta vara es la que dará la libertad a mi pueblo, así como la justicia a todos los animalitos y plantas con las que vivimos y que ya pocos conocen en realidad. Mis proyectos, mi profe, incluyen que los cerros que usted ve, así como todas las plantas y animales y piedras sean comuneros, y por lo tanto, por quienes las autoridades debemos luchar, siguiendo el pensamiento de los indios más viejos, que aunque usted no lo crea siguen vivos y nos guían con su palabra (Ceballos 2014:175).

\section{La etnohistoria y otras posibilidades para el pasado}

El despertar de la memoria étnica en Mocondino (2012) dejó en claro para la comunidad que el pasado no es algo que subyace petrificado y atrás, sino que es "algo" en continuo movimiento, y que al igual que el futuro ofrece varios caminos de acción, muchos de ellos trazados por la Palabra Mayor, la que emana de los abuelos, la gente de adelante, la que guía el camino y se encuentra en todas partes. El pasado es algo que, al igual que el futuro, está en continuo movimiento, porque bien puede aparecer un códice, un esqueleto, un artefacto, una narración o algún documento polvoriento que ofrezca nuevas perspectivas de lo que creíamos saber, y que cambie el esquema de verdad que tenemos. Quizá los huesos de Jesucristo, o el Cetro de alguien más poderoso que Alejandro, cuando las pirámides eran solo proyectos en la mente de genios. El pasado bien puede resurgir como elemento de resistencia en el presente, resignificando los hechos acaecidos, o potenciando los del presente, en particular desde las sombras a las que fueron sometidas las sociedades indígenas, tachadas de salvajes e incivilizadas:

LEY 89 DE 1890 Por la cual se determina la manera como deben ser gobernados 
los salvajes que vayan reduciéndose a la vida civilizada. El congreso de Colombia Decreta: CAPÍTULO I. Disposiciones generales. Artículo $1^{\circ}$. INEXEQUIBLE (Corte Constitucional Sentencia C-139 de 1996) La legislación general de la República no regirá entre los salvajes que vayan reduciéndose a la vida civilizada por medio de Misiones. En consecuencia, el gobierno, de acuerdo con la Autoridad eclesiástica, determinará la manera como esas incipientes sociedades deban ser gobernadas. Artículo $2^{\circ}$. Las comunidades de indígenas reducidas y a la vida civil tampoco se regirán por las leyes generales de la República en asuntos de Resguardos. En tal virtud se gobernarán por las disposiciones consignadas a continuación.

El pasado, después de todo, no es "algo" que está "detrás", sino algo que va adelante. Y en el "adelante" hay Cabildo y gobierno propio. Así lo expresa Luis Guillermo Vasco respecto de los Emberas, y que se replica entre los quillasingas de Mocondino:

Para decirlo mediante un ejemplo, la vida en esas sociedades es concebida como un desfile que se mueve de manera circular. Los primeros que vivieron, los antepasados, ya pasaron y van adelante. Ellos son quienes van marcando el sendero por donde hay que caminar. Los del futuro, los que no han pasado todavía, vienen atrás. Por ser circular el movimiento del desfile, los primeros en pasar no son gente que nunca volverá, sino que sigue estando, cumpliendo un papel en el presente y, por lo tanto, en el futuro (1991).

Esta concepción del pasado como algo que está adelante posibilitó que la institución colonial del Cabildo de Indígenas (réplica del Cabildo de las ciudades americanas, réplica a su vez del Cabildo de los municipios españoles), que en un primer momento se implantó para someter y gobernar a los americanos, reapareciera en el presente para resistir los más recientes intentos por desarticular por completo el accionar comunitario de los mocondinos ante las perspectivas de desarrollo que, en todo caso, no le benefician a ellos sino a una ciudad que, como casi todas en el mundo, practican el egoísmo del "crecimiento" descontrolado de sus fronteras físicas y mentales, como un cáncer que devora naturaleza y pueblos (Alimonda 2011).

\section{La Historia y la Etnohistoria como posibilidad narrativa}

La Historia, palabras más, palabras menos, ha sido entendida -en su acepción más común- como una serie de narraciones, más o menos "veraces" (¿científicas?) acerca del pasado (historiografía), entendido este como varios acontecimientos fijados en el tiempo que se pueden llegar a conocer, principalmente porque reposan en documentos escritos que dan (o pueden dar) testimonios "inmutables" acerca de los caminos, huellas o parte de ellas, recorridos por los pueblos y personas. La Historia, Encargada del pasado de la nación, luego de la sociedad, se ha vuelto recolectora de huellas y descifradora de archivos (Hartog 2007:13). Tradicionalmente la Historia (con mayúscula) ha sido reservada a los pueblos poseedores de escritura, bajo el entendido que es el documento escrito aquel que da una imagen estable de los acontecimientos de los que dan "fe", a diferencia de lo que ocurre con los pueblos de la siempre mutable tradición oral: $A$ esta escritura que invade al espacio y capitaliza al tiempo, se opone la palabra que no va lejos y que no tiene nada. [...] La palabra es aquí el cuerpo que significa [...] Solo hay escritura cuando el significante puede aislarse de la presencia [...]" (Certeau 1993:213).

Narraciones mutables del pasado que, lejos de ser "objetivas" en el sentido estrictamente científico, están condicionadas por las perspectivas políticas, económicas y de otro tipo, que se estatuyeron con la legitimación de los historiadores y academias de historia al servicio de próceres, políticos, banqueros, militares, curas y otras facciones del poder, tal como ocurrió con la llamada "Historia Patria" en muchos países latinoamericanos como Colombia, que se utilizó para consolidar los proyectos políticos que surgieron en las revoluciones "libertarias" del siglo XIX (Anderson 1993), y que poco atendieron la heterogeneidad inmersa en los nacientes Estados americanos, quedando muchos pueblos y naciones fracturados por fronteras inconsultas. Historiaficción patria que buscó consolidar un modelo hegemónico que Colombia, en la conmemoración de su "bicentenario" de existencia, reconoció su imposibilidad política ante una constitución que se asoma hacia la pluralidad ${ }^{1}$.

Cuando las sociedades respecto de las que se quiere narrar el pasado carecen de los elementos "objetivos" de la escritura para dar "fe" de los 
acontecimientos históricos, se habla de etnohistoria (Rodríguez 2000), entendida como una combinación de disciplinas que indagan acerca del pasado del vasto pluriverso que yace más allá de los límites epistemológicos que la llamada civilización occidental (eurocéntrica y hegemónica) impuso. En ese sentido, la etnohistoria se presenta en el terreno de lo mutable como otros caminos para el pasado, inmersos en lo nómada que subsiste en la tradición oral y costumbres de los pueblos y personas, y que constituye las otras voces de la historia (Guha 2002). Este tipo de historia está más asociada al quehacer de lo que podría denominarse como Estudios Adisciplinares, aquellos que van más allá de la interdisciplinariedad y rompen las fronteras del conocimiento a partir de la lógica (?) del sueño, de la periferia, del borde (Torres 2004). Una subversión a la (pretendida) historia universal del historicismo positivista eurocéntrico, del que Hartog se expresa de la siguiente manera en su carácter de dominador:

En el transcurso de la historia nunca han faltado las grandes "cronosofías", esas mezclas de profecías y periodizaciones, y más tarde los discursos de la historia universal -desde Bossuet hasta Marx, pasando por Voltaire, Hegel y Comte, sin olvidar a Spengler o Toynbee-. Movidas por interrogantes en torno al porvenir, tales construcciones, por diferentes que hayan sido los postulados en que se apoyaban (e independientemente de que al final de cuentas hayan privilegiado una perspectiva cíclica a una lineal), han buscado de manera fundamental aprehender las relaciones entre el pasado y el futuro; descubrirla, fijarlas: dominarlas para comprender y prever (Hartog 2007:33)

La etnohistoria es, así, una posibilidad creativa y revisionista de la historia oficial y "universal", ubicándose en la periferia de la Historia (Areces 2008), para posibilitar otras formas narrativas y de interpretación que coadyuven resistencias del presente, como lo hizo el Subcomandante Marcos desde la hermenéutica del sueño (1995). Para la etnohistoria del hombre andino es importante tener la posibilidad narrativa desde la poética como un derecho estratégico para las resistencias contemporáneas, más allá de lo que Guha denomina el estatismo histórico que escoge, de forma hegemónica, los acontecimientos que han de formar parte de la historia (2002).

\section{La Etnohistoria y la Etnoliteratura}

Las sociedades -en particular las denominadas étnicas o minoritarias- se expresan para sí y para las sociedades que les rodean y con quienes interactúan, mediante lo que puede denominarse como su etnoliteratura, entendida en un sentido amplio como todas aquellas producciones culturales susceptibles de transmitir, resignificar y perpetuar conocimientos $^{2}$. Las sociedades hablan, cuentan sus historias, las crean, las recrean, las reinterpretan, de forma colectiva (mitos, celebraciones) o individual (arte, trabajo). La etnoliteratura, o literatura de las sociedades minoritarias (jurídicamente hablando), ha estado lejos de la Literatura "oficial", de la misma forma que la Etnohistoria de la Historia, y sin embargo forman parte del mismo bando, como si se encontraran dentro de una cinta de Möebius del conocimiento, en la que el escritor se deja atrapar por lo que escucha, ve, lee, indaga, para narrar desde el sueño, aquello que la razón no puede comprender. Como ellos:

Doctor: nosotros no venimos a otra cosa que agradecerle nos atienda en nuestros requerimientos y nos ayude. Entendemos que usted de esto no vive, y le agradecemos que nos escuche, porque hay otros como usted que ni eso quieren de nosotros, porque somos indios. ¿Olemos mal, acaso? No, ¿no es cierto? Entonces díganos por qué, si nosotros demandamos ante el Alcalde la reconstrucción del título de resguardo según lo dice la Ley 89 que usted nos explicó, ahora mismo nos notifica el Comisario que el gobierno ha declarado extinto nuestro resguardo ${ }^{3}$. ¿Cómo le hacemos? Nosotros tenemos la razón, pero el gobierno de Ospina Pérez y los gamonales han terminado por ganarnos la batalla con esa horda de leguleyos que convencieron a la mayoría del pueblo que lo mejor era tener propiedad para ser civilizados.

Doctor: el Cabildo que ahora ve es apenas un brote, mientras que el de adelante es un huerto, una selva profunda que nos protege. 
Estamos cansados, pero firmes, porque somos tercos como el agua, y como esta, al fin encontraremos nuestro nivel. Ese día, le prometo doctor, volverá nuestra gente, para resistir, para ver en nosotros un adelante, una posibilidad para guarnecerse de las tormentas del futuro. El mismo que usted nos cuenta se ve terrible con eso de las bombas nucleares.

Por favor, doctor, regálenos una copia del expediente, en el que está la escritura 412 de 1927, que sé que les servirá a nuestros hijos para acordarse de lo que hemos hecho. Y escriba acerca de nosotros, no hable por nosotros. Seguro ya encontrará la forma de hacer conocer nuestra verdad:

Archivo Histórico de la Universidad de Nariño, escritura pública 412 de la Notaría Segunda de Pasto: Señor Fiscal del Honorable Tribunal Superior del Distrito Judicial de Pasto: Nosotros, Juan Bautista Jojoa, Clodomiro Pinto, Modesto Jojoa, Luis Emigio Naspirán y Eusebio Jojoa, Alcalde Mayor, Alcalde Segundo, Regidor mayor, Alguacil y Fiscal del actual cabildo de MOCONDINO, respectivamente, todos mayores de edad, natural de la sección ya expresada y vecinos de este Distrito Capital, a usted con nuestro acostumbrado respeto exponemos las siguientes razones: I. El título que demuestra la propiedad y dominio de nuestro resguardo de Mocondino, ha desaparecido, tal vez por la acción del tiempo, tal vez por no existir, sin que hasta la fecha tengamos dato alguno acerca de su existencia, encontrándonos por lo tanto imposibilitados de poder comprobar la posesión de tierras COMUNALES que en verdad nos pertenecen. II. Desde tiempos inmemoriales venimos usufructuando en nuestra calidad de indígenas del resguardo de Mocondino, toda la extensión de tierras que desde el tiempo del Rey se nos adjudicó, para poder atender así, a todas nuestras necesidades [...] V. La ley 89 de 1890 en su Arto. 12, ha previsto el caso de pérdida o de no existencia de un título de resguardo de una parcialidad. Este Arto. pues da la facultad de rehacer o de crear el título desaparecido, comprobando con el testimonio de cinco testigos de notorio abono, la posesión pacífica y no interrumpida por el lapso de treinta años, con la precisa determinación de sus linderos. -Idéntico procedimiento dispone el Arto. 39 del Decreto 74 de 1898 [...]

\section{A modo de conclusión: el título perdido}

Recuerdo que el primer documento que leí junto a ellos fue la Ley Primera, del Título Primero, del Libro Primero de las Leyes de Indias, que son el título originario que necesitan los pueblos originarios para legitimar su propiedad respecto de sus resguardos (Mayorga, 2013). El contenido de la misma desarrolla una visión imperial del mundo impuesta por Roma mediante sus reyes y autoridades eclesiásticas, las que continuaron en la república hasta 1991 por medio de la Ley 89 de 1890 y el Concordato de 1887. Y ese poder subsiste en muchos niveles todavía como la educación privada, en poder del cristianismo católico.

Para nosotros es problemático separarnos del cura, profe. Nuestros comuneros son bien católicos y le hacen caso al padre, casi más que a nuestras autoridades: ¡Hasta nos toca ir a Misa antes de posesionarnos como Autoridades!Y eso es porque nosotros somos nuevos a pesar de que nuestros cargos son ancestrales. Hace menos de tres años acá no había Cabildo, pues según cuentan los mayores y ustedes los estudiosos, este se acabó con la propiedad privada que llegó detrás de una horda de abogados predicando que la propiedad privada nos integraría al desarrollo y la modernidad del país. No ve ahora, la Junta de Acción Comunal está queriendo que la casa comunitaria sea de propiedad privada de la Junta. Privada al fin y al cabo, por eso le terminaron colocando esas rejas metálicas. Se ve más como una cárcel que como un lugar para el pensamiento y la acción ${ }^{4}$.

Verá profe que nosotros somos católicos, porque así nos dejaron nuestros padres, y sus padres antes que ellos. Somos cristianos y conocemos el libro del Rey. Recuerdo que el profesor Dumer nos habló de Juan Chiles, y de cómo conocer el libro del Rey le permitió reivindicar los derechos de 
su pueblo en las Cortes españolas. Y eso porque ante la ley el indio era igual que el español, tal y como lo dice el Libro Sexto, Título Primero de las Leyes de Indias que usted nos hizo leer junto a los documentos del archivo que encontró el profesor Jorge Perugache. Aquí en mi casa están todos esos documentos, menos el título de resguardo, que aunque perdido de los archivos notariales, hay una copia de este en las piedras Churas [petroglifos] que viven en nuestro territorio. Aunque sería bueno permanecer algunos años entre Bogotá, Popayán, Quito, Sevilla y Pasto escudriñando los archivos

\author{
históricos. Usted y la Universidad nos \\ pueden apoyar.
}

\section{Agradecimientos}

A los comuneros de Mocondino (Colombia) en su despertar; a la Facultad de Derecho y Centro de Investigaciones Sociojurídicas de la Universidad Cooperativa de Colombia; al profesor Dumer Mamián y el equipo del Instituto Andino de Artes Populares IADAP de la Universidad de Nariño (Jorge Andrés Perugache S., Jaime Cañizares, Ximena Rosero Andrade y Marisol Verdugo Miranda).A los evaluadores, por su tiempo, conocimiento y paciencia ${ }^{5}$.

\section{Referencias Citadas}

Afanador, C.

1977 Reseña Etnohistórica del Valle de Atriz. Bogotá: Universidad de los Andes.

Acosta, A. \& Esperanza Martínez (Compiladores)

2011 Los derechos de la naturaleza: de la filosofía a la política. Quito: Abya Yala.

Bibliography Allroggen, N. \& Arturo, J.

2013 Mocondino y los derechos comunitarios. Agua y conflictos ambientales. Escenarios Socio Jurídicos $N^{o} 7$, Disponible en http://www.redsociojuridica.org/escenarios/ edicion-7/Mocondino-y-los-Derechos-Comunitarios.pdf.

Alimonda, H. (Coordinador).

2011 La naturaleza colonizada. Ecología Política y minería en América latina. Buenos Aires: CLACSO.

Anderson, B.

1993 Las comunidades imaginadas. México: Fondo de Cultura Económica Disponible en http://www.perio.unlp. edu.ar/catedras/system/files/anderson_benedict-_comunidades_imaginadas.pdf.

Areces, N.

2008 La etnohistoria y los estudios regionales. Andes $N^{o} 19$, 15-28 Disponible en http://www.scielo.org.ar/pdf/andes/ n19/n19a01.

Bengoa, J.

2000 La emergencia indígena en América Latina. Santiago: Fondo de Cultura Económica.

Büschges, C., \& Pfaff-Czarnecka, J.

2003 La etnización de lo político. Etnicidad, Estado-Nación y globalización en la Sudamérica. Memorias del XII Congreso Colombiano de Historia. Popayán, Cauca, Colombia: disponible en http://www.uni-bielefeld.de/tdrc/ag_sozanth/downloads/ BueschgesPfaff.pdf.

Calderón, C.

1895 Núñez y la Regeneración. Bogotá: Sevilla: imprenta de Izquierdo. Disponible en http://www.banrepcultural. org/sites/default/files/brblaa769063.pdf.

Ceballos, F.

2013 El agua: un asunto de justicia en comunidad con el planeta. En Agua Para La Vida:Memorias De La IV Semana
Nacional de la Ciencia, la Teconología y la Innovación, Nariño 2012. Pasto: Universidad Mariana.

Ceballos, F.

2014 Aproximaciones a los derechos de la naturaleza y el buen vivir desde los pueblos originarios en Colombia: Retos frente a los desafíos ambientales del siglo XXI. Boletín de Antropología, Vol. 29, № 47:159-178.

Ceballos, F.

2014 Relatos en el fin del mundo (Inédito). Nariño, Colombia: Maestría en Etnoliteratura Universidad de Nariño.

Certeau, M. d.

1993 La escritura de la historia. México D.F.: Universidad Iberoamericana.

Chaves, M.

1986 Realidades y perspectivas de la población indígena del sur de Colombia: reflexiones sobre los resguardos indígenas de Nariño. San Juan de Pasto.

Chaves, $\mathrm{M}$.

2001 Discursos subalternos de identidad y movimiento indígena en el Putumayo. Movimientos sociales, estado y democracia en Colombia, UNAL-ICANH.

Fals-Borda, O.

1959 El vínculo con la tierra y su evolución en el departamento de Nariño. Revista de la academia de ciencias exactas, físicas y naturales, 10:9-14.

Gross, C.

2012 Políticas de la etnicidad: identidad, Estado y modernidad. Bogotá: Instituto Colombiano de Antropología e Historia ICANH Disponible en http://biblioteca.icanh.gov. co/DOCS/MARC/texto/306.08998G877p.pdf.

Guha, R.

2002 Las voces de la historia. Estudios Subalternos. Barcelona: Crítica.

Hartog, F.

2007 Regímenes de historicidad. Presentismo y experiencias del tiempo. México D.F.: Universidad Iberoamericana.

Lopera-Mesa, G.

2010 Territorios, identidades y jurisdicciones en disputa. Universitas Humanística, 69:61-68. 
Mamián, D.

2000 Rostros y rastros de un camino por andar. Mopa-Mopa, 14:75-88.

Malagón, M.

2006 La Regeneración, la Constitución de 1886 y el papel de la Iglesia Católica. Civilizar $N^{\circ} 11$ Universidad Sergio Arboleda, Disponible en http://www.usergioarboleda.edu. co/civilizar/revista11/regeneracion_constitucion.pdf.

Martínez, S., \& Portilla, M.

1992 Presencia y descomposición del resguardo de Catambuco en el siglo xx (Trabajo de grado). San Juan de Pasto, Colombia. Biblioteca general Universidad de Nariño.

Mayorga, F.

2013 Norma general, norma especial: el Código Civil de 1887 y la Ley 89 de 1890, un caso de regulación protectora de las minorías durante la Regeneración. Academia Colombiana de Historia Disponible en https://www.youtube.com/ watch?v=LRzK8Y4JmX4.

Melo, M.

1992 El manejo y conocimiento de los Andes. Corregimiento de Genoy, Municipio de Pasto. Departamento de Antropología Universidad del Cauca: Trabajo de Grado.

Muñoz, L.

2003 Historia de Pandiaco. Desde la Colonia a la República Siglos XVI-XX. San Juan de Pasto: Academia Nariñense de Historia.

Perugache, J.

2012 Pasados de lucha, caminos para la lucha. Historia y memoria en los andes suroccidentales. XIV Congreso de Antropología. Medellín, Antioquia, Colombia.

Perugache, J.

2013 Nuevos o viejos actores étnicos? Reindigenización y construcción de ciudadanías. En D.M. (C), Memorias en Movimiento (págs. 49-71). Pasto: Universidad de Nariño.

Perugache, J.

2014 La disolución de los resguardos quisillangas del valle de Atriz del suroccidente. Procesos Históricos, 26:140-157.
Rappaport, J.

2005 Cumbe renaciente: una historia etnográfica andina. ICANH.

Rodríguez, $\mathrm{M}$.

2000 Etnohistoria: ¿la ciencia de la diversidad cultural? Exploración acerca de la constitución del término y del desarrollo de la teoría y su método. Boletín Antropológico $N^{o}$ 50, 5-28 Disponible en http://www.saber.ula.ve/bitstream/123456789/18418/3/miguel_rodriguez.pdf.

Bibliography Torres, A.

2004 Por una investigación desde el margen. La práctica investigativa en ciencias sociales, 62-79 Disponible en http:// biblioteca.clacso.edu.ar/Colombia/dcs-upn/20121130051523/ investigacion.pdf.

Vasco, L.

1991 (11 de Agosto) El tiempo y la historia entre los indígenas Embera. Magazín Dominical El Espaectador.

Vasco, L.

2010 Los pueblos originarios y la Independencia. Cátedra de pensamiento social Orlando Fals Borda: “¿Independencia o revoluciones burguesas?”. Bogotá, Colombia: Universidad Distrital Francisco José de Caldas. Obtenido de Luguiva. net.

Vasco, L.

2011 (05 de Transcripción revisada y corregida de la intervención en el Foro "Etnicidad, desigualdad y diversidad: 20 años de la Constitución del 91", realizado en la Universidad Externado de Colombia en mayo de 2011). Constitución de 1991: integración jurídica de las sociedades indígenas a la sociedad nacional colombiana. Obtenido de http://luguiva. net: http://luguiva.net/articulos/detalle.aspx?id=90

Wachtel, N.

1999 Memoria e Historia. Revista Colombiana de Antropología, 35:70-90

Zambrano, C.

2001 Conflictos por la hegemonía regional: un análisis del movimiento social y étnico del macizo colombiano. En M. A. (editor), Movimientos sociales, estado y democracia en Colombia. Bogotá: UNAL-ICANH.

\section{Notas}

1 Si bien el 2010 se presentó como el año del bicentenario de la independencia y la historia de Colombia (y así en otros países latinoamericanos), el proyecto de Estado-Nación colombiano no se consolidó sino hasta la promulgación de la Constitución Política de 1886, donde aparece la República de Colombia como tal, apoyada en la "poética" del himno nacional escrito por Rafael Núñez (base de la llamada Historia Patria), en la que se oficializó la historia de próceres y hazañas que se repiten -aún hoy- hasta el cansancio en las escuelas como la verdad de los hechos.

2 La etnoliteratura ha tenido dos acepciones básicas: 1) Como una literatura "menor" respecto de la Literatura "oficial", por hundir sus raíces en la tradición oral y otras expresiones culturales (como el carnaval, por ejemplo), mutables y de origen colectivo y 2) Como fuente para el quehacer de los científicos sociales que estudian a las, jurídicamente hablando, sociedades minoritarias (antropólogos, historiadores, sociólogos, abogados). Una tercera perspectiva -de la que hacemos eco- hace de la etnoliteratura una posibilidad creativa, tanto para las sociedades étnicas (en su conjunto o como individuos) como para los investigadores que interactúan con estas, siendo no ya una Literatura menor, sino un género de igual "jerarquía" que otros como la ciencia ficción, y una posibilidad expresiva para los científicos sociales (Ceballos 2014b).

3 Artículo $12^{\circ}$. En caso de haber perdido una parcialidad sus títulos por caso fortuito o por maquinaciones dolosas y especulativas de algunas personas, comprobará su derecho sobre el resguardo por el hecho de la posesión judicial o no disputada por el término de treinta años, en caso que no se cuente con esa solemnidad, y de acuerdo con lo dispuesto en el Código Civil. Este último requisito de la posesión pacífica se acredita por el testimonio durado de cinco testigos de notorio abono, examinados por citación del Fiscal del circuito, los que expresarán lo que les conste o hayan oído decir a sus predecesores, sobre la posesión y linderos del resguardo. 
Artículo 13. Contra el derecho de los indígenas que conserven títulos de sus resguardos, y que hayan sido desposeídos de estos de una manera violenta o dolosa no podrán oponerse ni serán admisibles excepciones perentorias de ninguna clase. En tal virtud, los indígenas perjudicados por algunos de los medios aquí dichos podrán demandar la posesión ejecutando las acciones judiciales convenientes.

$4 \quad$ En el Juzgado Sexto Civil Municipal de Pasto se adelanta el proceso de pertenencia ordinario 2013-0491, interpuesto por la Junta de Acción Comunal en contra el extinto Sindicato Agrario de Mocondino para que se le conceda el título de propiedad de la Casa Comunitaria tras más de veinte años de posesión material. La casa había sido cedida por el Sindicato Agrario tras su disolución en la segunda mitad del siglo XX a la Junta de Acción Comunal, estando edificada dentro del extinto resguardo indígena de Mocondino.

5 Artículo de reflexión derivado de ponencia presentada en el simposio Diversidad y posibilidades en las etnohistorias andinas del IX Congreso Internacional de Etnohistoria, Arica, Chile. Resultado de los proyectos 1) Plan de trabajo para Semilleros de Investigación "Antecedentes históricos y jurídicos de la disolución y reestructuración de los resguardos indígenas quillasingas de Jenoy y Mocondino" de la Convocatoria Colciencias 617 de 2013, ejecutado por el grupo de investigación La Minga de la Universidad Cooperativa de Colombia. 2) "La disolución y reestructuración de los resguardos quillasingas del Valle de Atriz", financiado por la Vicerrectoría de Investigaciones, Posgrados y Relaciones Internacionales y ejecutado por el grupo de investigación IADAP de la Universidad de Nariño. 
